\title{
A Quantitative Study of the Direct Use of Kerosene for Lighting in Sri Lanka Households
}

\author{
L. C. A. DE S. WIJESINGHE \\ Natural Resources, Energy and Science Authority of Sri Lanka, \\ Maitland Place, Colombo 7, Sri Lanka
}

(Date of receipt: 20 February 1984)

(Date of acceptance: 29 March 1984)

\begin{abstract}
It is known that over $80 \%$ of households in Sri Lanka use kerosene for lighting; but there is no reliable information on the quantity used. The present study which was based on a stratified sample was carried out to obtain quantitative information on kerosene consumption in the household sector. The country was divided into four zones. Households were stratified by zones and by sectors within the zones, and sample households were selected at random in proportion to the number of households in each stratum. In the sample households, kerosene consumption (for lighting) in a 24-hour period was measured and other information collected. The mean per caput/day consumption was estimated at $16.8 \pm 6.2 \mathrm{ml}, 50.9 \pm 3.4 \mathrm{ml}$ and $75.2 \pm 11.8 \mathrm{ml}$, and the mean per household/day consumption at $95.3 \pm 35.3 \mathrm{ml}, 286.5 \pm 19.5 \mathrm{ml}$ and $349.0 \pm 52.3 \mathrm{ml}$ in the urban, rural and estate sectors respectively. The total consumption for the year was estimated at $264 \times 10^{6}$ litres. The 'bottle lamp' (without a chimney) was the most common type of lamp in use. Half the households in the whole sample and $62.1 \%$ in the rural sector were receiving 'kerosene stamps' on which they could obtain kerosene up to a certain value a month free of charge.
\end{abstract}

\section{Introduction}

The Sri Lanka census of population and housing carried out in 1981 showed that $82.4 \%$ of the houses used kerosene for lighting. ${ }^{4}$ This dependence of a large proportion of the population (consisting mainly of the rural poor) on kerosene for providing a basic need prompted the government which has a monopoly over the production and distribution of kerosene to introduce a general price subsidy on this product following the fuel crisis of 1973-74. Hence, although there was a sharp initial price increase in January, 1?74, thereafter, while the prices of other petroleum products kept rising steeply, the price of kerosene remained low. This was the position till 1979 when the government reduced the subsidy on kerosene, and the sale price rose from Rs. 3.48 to Rs. 10.68 a gallon.* Simultaneously a "kerosene stamp" scheme was introduced to enable the needy to obtain kerosene for lighting free of charge up to a certain value in a month. After 1979 there have been more price increases, of which the last two were in March and in July, 1983, during the period of this study. The results of these two increases was to raise the price of kerosene from Rs. 17.68 to Rs. 29.97 a gallon. Even with the last increase there continued to be a subsidy though at a much reduced level.

* In June, 1983, 1 US $\$=$ Rs. 23. One gallon $=4.546$ litres. 
As the price of kerosene in the open market was a subsidised one, there was a general belief that industrialists and others were using kerosene in place of other fuels to benefit by the subsidy. One view was that the proportion so used was small, 6,8 but a World Bank mission was of the opposite view and has stated, "a large proportion of the kerosene consumption (well over half) is in uses for which the subsidy was never intended, as an industrial heating fuel, in standby generators, as a cooking fuel for the better off households, etc."9 The data on local sales of kerosene published by the Ceylon Petroleum Corporation give the total consumption in the country, but there is no information on the quantity used for lighting; hence the conflicting views on how much of the kerosene is diverted to other uses.

The writer decided to carry out a sample study of kerosene directly used in household lighting with the main objective of estimating the quantity so used. Information was also collected on the types of kerosene lamps used and on whether the sample households were receiving kerosene stamps. This study was combined with one on biomass fuel consumption. The biomass fuel study has been described elsewhere, ${ }^{10}$ while the present paper deals with the study on kerosene consumption.

\section{Methodology}

\subsection{Sampling design and procedure}

In the biomass fuel study with which the kerosene consumption study was combined three categories of biomass fuel were recognized, and on the basis of predictable variations in the composition of the biomass fuel mix, the country was divided into four zones. This was the first step in a two-stage stratification of the population. The second stage was the division of the population (and the households) in each zone into three sectors, urban, rural and estate, recognized in the national census. This stratification developed for the biomass fuel consumption study was considered acceptable for the kerosene consumption study, and the same sample households were used for both investigations. In fact the data for both studies were collected at the same time when the investigating team visited the sample households.

The four zones into which the country was divided are:

1. Dry lowlands: Administrative districts: Hambantota, Amparai, Anuradhapura, Polonnaruwa, Moneragala, Trincomalee, Badulla (1/4), Puttalam (1/4), Mannar, Vavuniya, Jaffna, Batticaloa, Mullativu;

2. Up-country, Tea: Administrative districts: Kandy, Matale, Nuwara Eliya, Badulla (3/4); 
3. Coconut: Administrative districts: Colombo, Kurunegala, Gampaha, Galle, Matara, Puttalam (3/4);

4. Rubber: Administrative districts: Kalutara, Ratnapura, Kegalle.

Two of the 24 districts (Badulla and Puttalam) were each divided between two zones, the fraction given against their names denoting the proportion of the households assigned to each zone. Except in these two cases the district boundaries were used to define the boundaries of the zones and each zone therefore does not represent a completely homogeneous unit. A certain amount of overlap was unavoidable; for example, although Zone 4 is predominantly a rubber growing area, there are some tea plantations within it. The zonation is shown in Figure 1.

Stratification of the population and the households into the three sectors, urban, rural and estate was done on the basis of the data provided by the 1981 census. ${ }^{3,5}$ The urban sector comprises the areas falling within the limits of municipal councils, urban councils, and town councils. The rural sector consists of village council areas but excludes the areas falling into the estate sector. The estate sector includes crop plantation estates of 8.1 ha ( 20 acres) or more in area and with 10 or more resident labourers. Since the estate sector populations (as defined in the census report) in the Dry lowland and Coconut Zones are relatively small, and moreover, as the domestic biomass fuel consumption and kerosene consumption patterns in these two strata were not expected to be different from those in the corresponding rural sector strata, the estate sector in each of these zones was combined with that of the corresponding rural sector. The population and the households were, accordingly, divided into ten strata. They are Dry lowlands, urban (IU); Dry lowlands, rural (1R); Upcountry, Tea, urban (2U); Upcountry, Tea rural (2R); Upcountry, Tea, estate (2E); Coconut, urban (3U); Coconut, rural (3R); Rubber, urban (4U); Rubber, rural (4R); and Rubber, estate (4E).

The total sample size was set at around 500 households and the allocation of the sample among the strata was done in proportion to the number of households within each stratum. However, to keep the sampling error down, the minimum sample size for a stratum was set at 10 households. The total sample finally consisted of 518 households.

Within each stratum, the districts and the locations within the districts where the sampling was to be done were chosen randomly. Having decided on a location the team went to the spot and adopted a random procedure to select the households, e.g. the team would proceed along a randomly selected road or pathway and in one case select every third housing unit on the right side and in another pick every fifth dwelling on the left, and so on, thereby simulating a "circular sampling system." 




Figure 1. Map showing the four zones. 


\subsection{Data Collection}

The team that collected the data comprised two Staff Assistants (both physical science graduates) and a labourer. The writer accompanied the team in the early stages and occasionally afterwards. Each sample household was visited twice. On the first visit the purpose of the study was explained to the senior householder present. A note was made of whether the house was provided with electricity, and if the household used kerosene lamps either as a supplement to electric lights or as the only source of lighting, the team proceeded to measure the quantity of kerosene available for use in the lamps. The kerosene oil in the lamps was drained into a measuring cylinder into which was also added the kerosene that was usually found in a storage container in the house. The total volume was measured to the nearest $5 \mathrm{ml}$ and the oil was then poured back into the lamps and storage container. The investigating team was instructed that, if they came across any households that used kerosene both for lighting and for cooking, the oil for use in lighting should be measured and stored separately. Instructions were also given that, if any households were using kerosene for generating electricity, the quantity of oil so used was not to be included in this study. In some households there was insufficient kerosene for use during the night of the visit and the householder expected to purchase some before nightfall. In such cases the householder was instructed to keep a careful record of the quantity and the cost of the kerosene purchased. Finally the team instructed the household not to deviate from its usual practice in the use of lamps that night.

The team revisited the household 24 hours later and measured the quantity of kerosene remaining. If any oil was purchased, its volume was determined in millilitres by measuring a quantity equal to that which was purchased, and a further check was made by comparing the quantity with the price paid. From the data collected, the quantity consumed by the lamps during the previous night was obtained. The team also recorded the number and types of lamps used by the household and the number of members present during the previous night. A note was also made of whether the household was receiving kerosene stamps. The field work started. in February and was completed in September, 1983.

\subsection{Kerosene Consumption.}

\section{Results}

The mean per caput/day consumption and the mean per household/day consumption of kerosene for lighting in the 10 strata as calculated from the sample data are given in Table 1. Taking the rural sector only, the lowest per caput and per household values are in the Dry lowlands (1R) and the highest in the Coconut Zone (2R). Tests of significance ( $t$ test) indicated that the difference between the mean values of $1 \mathrm{R}$ and $2 \mathrm{R}$ both for the per caput consumption and the per household consump- 
tion were highly significant. In the mean per caput values, the difference between $2 R$ and $3 R$ and between $2 R$ and $4 R$ were also highly significant. The other differences between the rural sector means were not statistically significant.

Table 1. Data on kerosene consumption for lighting

\begin{tabular}{ccccc}
\hline \multirow{2}{*}{ Stratum } & \multicolumn{2}{c}{ Per caput consumption } & \multicolumn{2}{c}{ Per household consumption } \\
\cline { 2 - 5 } \cline { 4 - 5 } & Mean/day in $m l$ & SE of mean & Mean/day in $m l$ & SE of mean \\
\hline & & & & \\
1U & 12.8 & 6.17 & 92.3 & 44.35 \\
3U & 18.3 & 11.44 & 117.5 & 77.57 \\
4U & 17.8 & 4.43 & 93.6 & 22.09 \\
1R & 17.6 & 6.28 & 90.0 & 37.32 \\
2R & 43.8 & 3.03 & 263.6 & 18.07 \\
3R & 66.7 & 4.84 & 352.0 & 27.83 \\
4R & 50.4 & 2.95 & 274.1 & 16.70 \\
2E & 52.0 & 3.52 & 302.7 & 19.36 \\
4E & 77.6 & 5.76 & 384.4 & 25.23 \\
& 70.5 & 13.37 & 278.3 & 54.01 \\
\hline
\end{tabular}

In all the zones the urban sector mean was very much lower than the corresponding rural and estate sector means. This was expected since many urban households use electricity and not kerosene for lighting. Taking the country as a whole, the per caput/day mean consumption values were $16.8 \pm 6.2 \mathrm{ml}, 50.9 \pm 3.4 \mathrm{ml}$, and $75.2 \pm 11.8 \mathrm{ml}$, and the per household/day means were $95.3 \pm 35.3 \mathrm{ml} ; 286.5 \pm 19.5$ $\mathrm{ml}$ and $349.0 \pm 52.3 \mathrm{ml}$ in the urban, rural and estate sectors respectively.

Taking the rural sector which is the dominant sector in terms of both size and total household consumption of kerosene, the sample households were classified according to the number of mëmbers present in the household at the time of the study. The mean household consumption was calculated for each class and these values (for the range two to nine members/household) were plotted against household size to indicate the relationship between the mean household consumption and the number of persons comprising the household. The data from the four rural sector strata were plotted separately. "The values for households with one member and with over nine members were omitted in plotting the data as the number of households representing these classes was very small.

To determine the function that would suitably express the relationship between household consumption and household size, two functions were tested; these are the equation $y=a+b x$ which connotes a linear relationship and the equation $y=\beta x \infty$ which connotes a curvilinear relationship. Although it is generally expected that the relationship between household consumption and household size would follow the pattern of the "law of diminishing returns" and hence that Cobb 


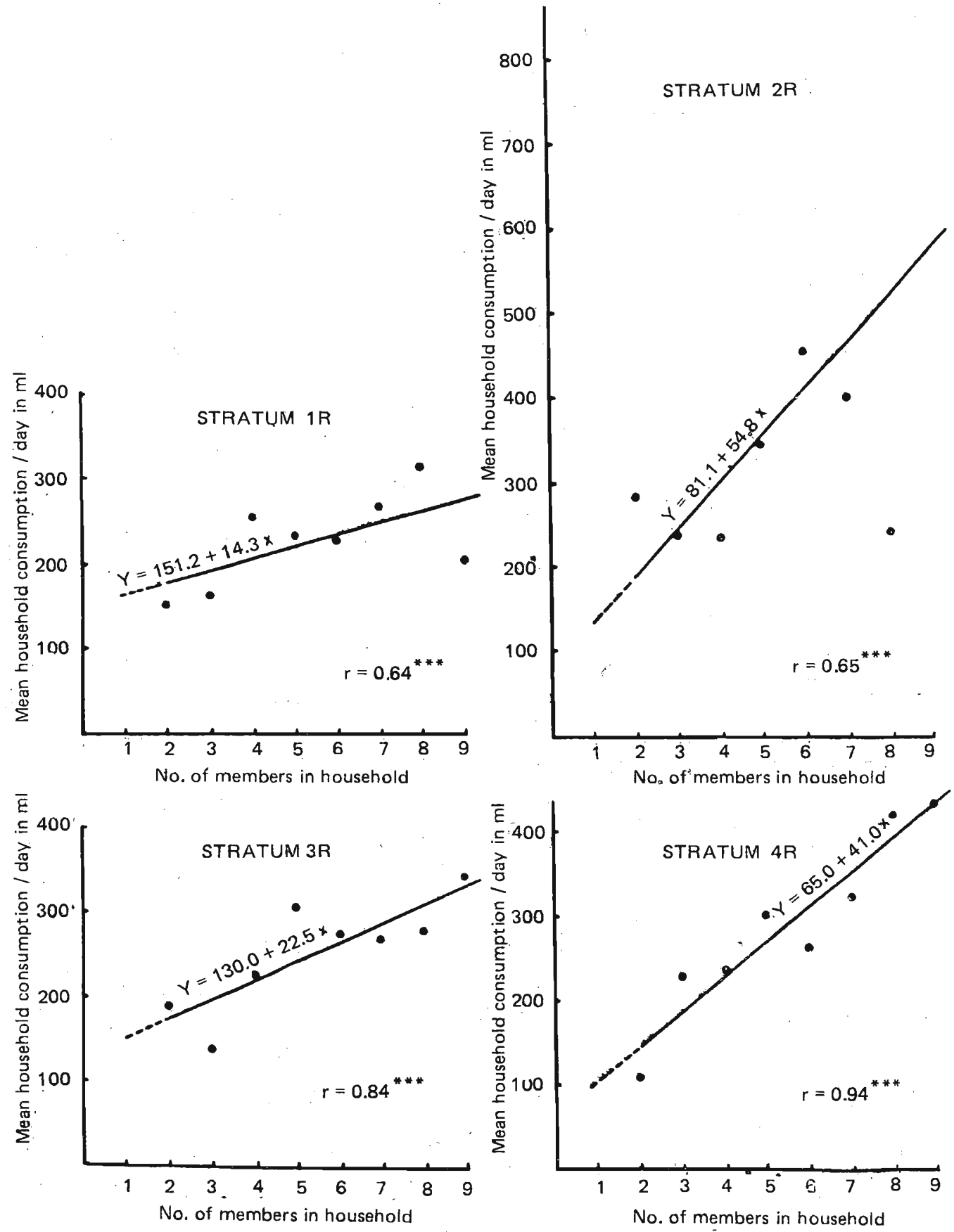

Figure 2. Relationship between mean household consumption and household size in the four rural sector strata. 
Douglas' function ( $y=\beta x \propto$ ) would express the relationship better, it was found in this analysis that in all four cases the goodness of fit of the two functions (as indicated by the coefficients of determination) within the range covered by the graphs did not differ significantly. It was hence decided to fit the simpler linear regression line (Figure 2). The regressions indicate that the per household consumption increases with increase in household size. It was therefore decided, for the rural sector, to avoid using the stratum mean directly for estimating total consumption, and instead, to use the mean consumption per household for each household size as derived from the regression equation.

To compute the total consumption of kerosene it was necessary to estimate the number of households in each stratum in 1983 . from the 1981 census data, and this was done by using the average annual growth rates in housing in the period 1971 1981 which have been published by the Department of Census and Statistics. ${ }^{4}$ The estimated number of households in each of the rural sector strata was then distributed among nine categories, namely, households with 1-member, 2-members, 3-members, and so on up to 9 and more members based on similar data on the distribution of housing units given in the census publication. ${ }^{4}$ The figures so obtained were used together with the corresponding mean per household consumption values estimated from the regression equation (the mean consumption of one-member households being obtained by extrapolation) to compute the total consumption in the rural sector.

A housing unit is generally occupied by a single household, but in a very small percentage of cases two or more households occupy a single house. Hence there is some approximation in using the data on housing units for estimating the increase in the number of households from 1981 to 1983 and for distributing the households according to size. This was unavoidable since more direct information on households was not available; but the resulting error is probably negligible.

Table 2 gives the estimated number of households in each.rural sector stratum classified according to household size, the estimated mean per household/day consumption (as derived from the regression equation) and the estimated total consumption for the year 1983.

For the urban and estate sectors which are much less important than the rural sector in this study, the mean household consumption and the estimated number of households were used for computing the annual consumption. The results are shown in Table 3. Based on the estimates presented in Tables 2 and 3, the 1983 consumption of kerosene for direct use in lighting in the entire country is reckoned at $264 \times 10^{6}$ litres. 


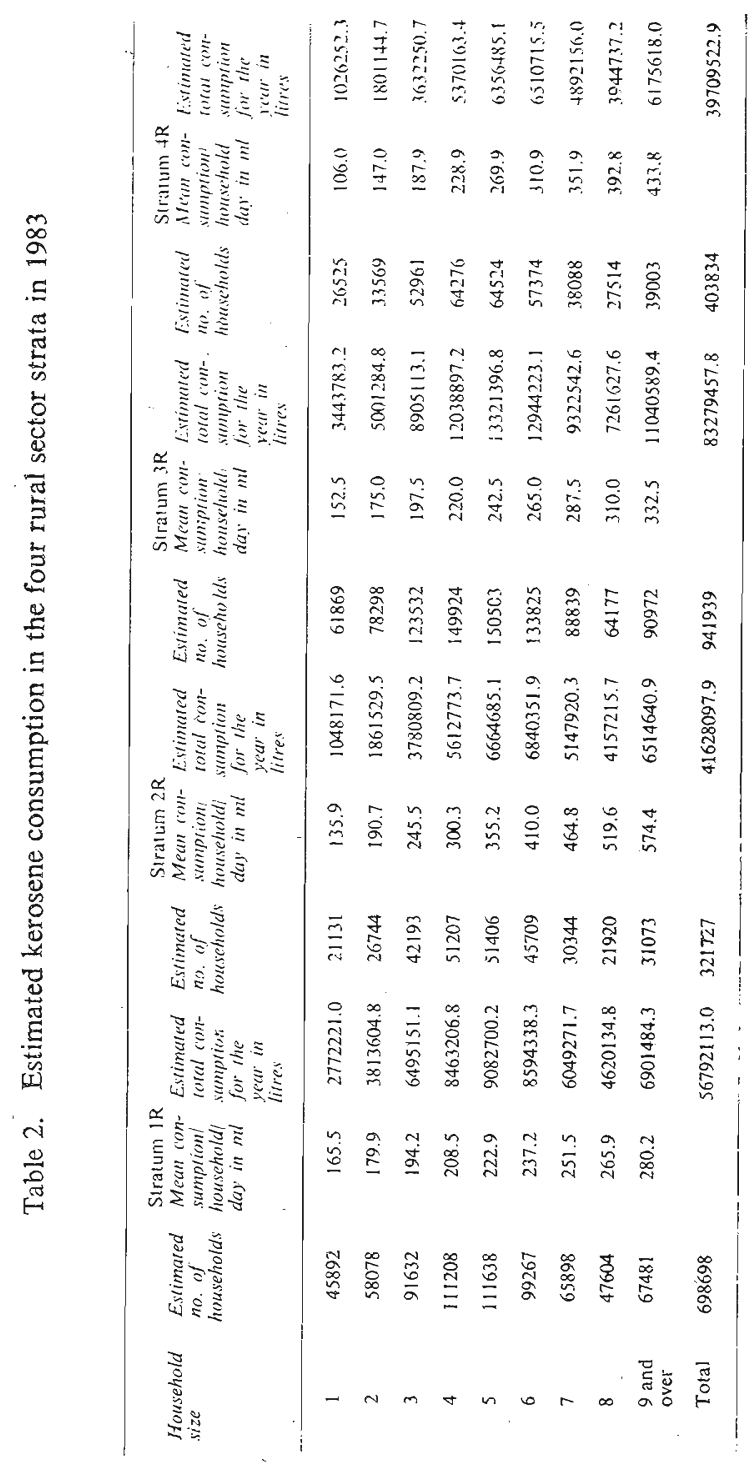


Table 3. Estimated kerosene consumption in the urban and estate sector strata in 1983

\begin{tabular}{cccc}
\hline Stratum & $\begin{array}{c}\text { Mean household } \\
\text { consumption in } m l\end{array}$ & $\begin{array}{c}\text { Estimated no. } \\
\text { of households }\end{array}$ & $\begin{array}{c}\text { Estimated total } \\
\text { consumption for } \\
\text { the year in litres }\end{array}$ \\
\hline IU & 92.3 & 124066 & 4179721.5 \\
2U & 11.5 & 40094 & 1719531.4 \\
3U & 93.6 & 330311 & 11284745.0 \\
4U & 90.0 & 48597 & 1596411.5 \\
$2 \mathrm{E}$ & 384.4 & 138473 & 19428592.7 \\
$4 \mathrm{E}$ & 278.3 & 44721 & 4542736.8 \\
Total & & 726262 & 42751738.9 \\
\hline
\end{tabular}

This study revealed that in many households which use biomass fuel for cooking, a small quantity of kerosene is used as an ignition fuel to start the kitchen fire in the morning. This could not be measured separately and was included in the quantity recorded as kerosene used for lighting.

\subsection{Lighting}

In the rural and estate sectors, of the 421 sample households, $404(96.0 \%)$ used only kerosene lamps for lighting, while in the total sample covering all three sectors, of the 518 households, $429(82.8 \%)$ depended entirely on kerosene for lighting.

The naked flame "bottle lamp" was found to be the most common kerosene lamp in use in the households. It consists of a bottle of convenient size or a discarded electric bulb suitably modified, and a wick in a wick-holder. The wick-holder is generally placed loosely on top of the bottle with the wick dipping into the oil in the bottle. There is no chimney. Often, the householder adopts some device to keep the lamp steady and prevent it from being knocked over. This generally consists of either partially filling the bottle with pebbles or sand or placing the bottle in an empty can (Figures 3-6).

The other types of lamps in use were the table type chimney lamp, the suspended chimney-lamp, the hurricane lamp, and the mantle type pressure lamp. The data on the use of bottle lamps and of other types of lamps by the sample households are given in Table 4. 




Figure 3. Bottle lamps placed in empty cans to keep them steady.

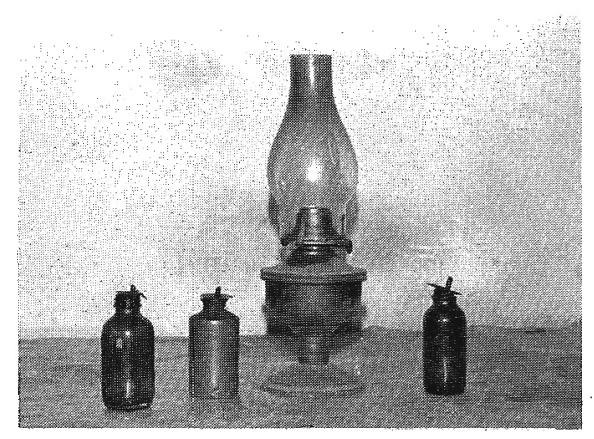

Figure 5. Three bottle lamps and a table model chimney lamp.

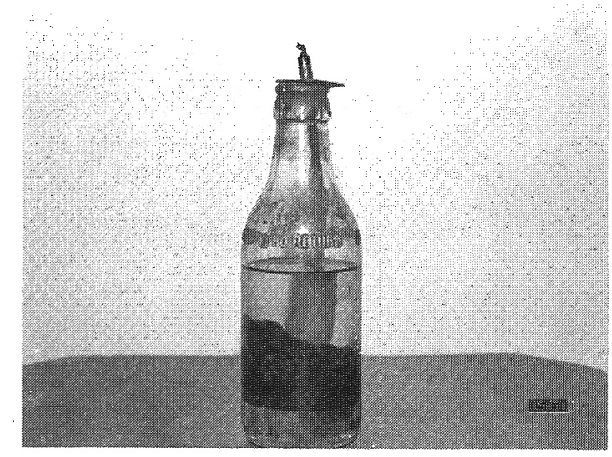

Figure 4. Bottle lamp partially filled with coarse sand.

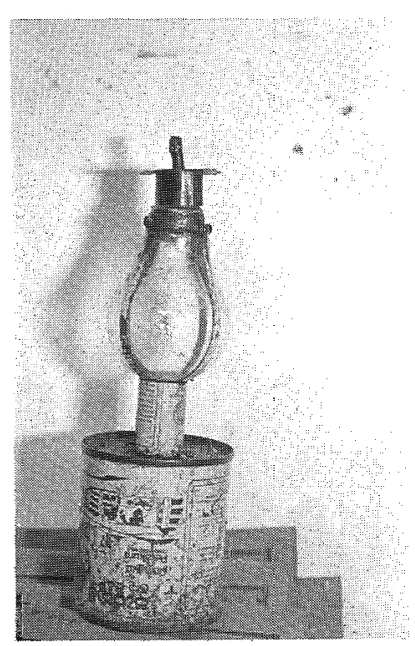

Figure 6. Lamp made out of a discarded electric bulb and fixed on to a stand 


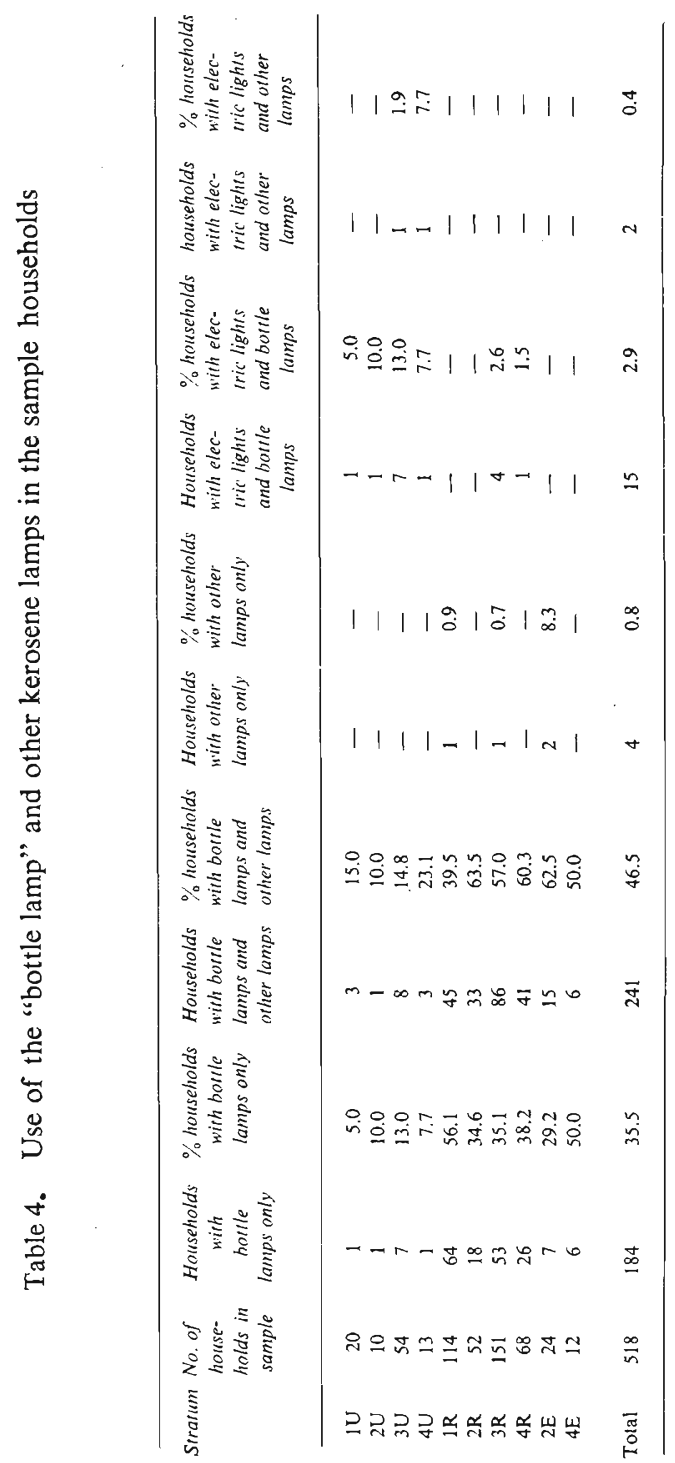


Seventy two households (not accounted for in Table 4) used only electricity for lighting; one of them used a kerosene-driven generator, two used a 12-volt storage battery connected to low-wattage fluorescent tubes (a system popularised by the National Engineering Research and Development Centre), and the other 69 obtained their electricity from the national power supply. Of the 17 households which used both electricity and kerosene lamps for lighting (included in Table 4), three used a storage battery and the others used the power supply.

\subsection{Kerosene Stamps}

In the total sample of 518 households, $258(50 \%)$ reported that they were receiving kerosene stamps, while in the rural sector, of the 385 households in the sample 239 $(62 \%)$ were receiving stamps. The data for all the strata are given in Table 5.

Table 5. Sample households receiving kerosene stamps

\begin{tabular}{cccc}
\hline Stratum & $\begin{array}{c}\text { No. of households } \\
\text { in the sample }\end{array}$ & $\begin{array}{c}\text { No.of households } \\
\text { receiving kerosene } \\
\text { stamps }\end{array}$ & $\begin{array}{c}\% \text { households receiving } \\
\text { kerosene stamps }\end{array}$ \\
\hline 1 U & 20 & 3 & 15.0 \\
2 U & 10 & -12 & - \\
3 U & 54 & 3 & 22.2 \\
4 U & 13 & 82 & 71.9 \\
1 R & 114 & 27 & 51.9 \\
2 R & 52 & 89 & 58.9 \\
3 R & 151 & 41 & 60.3 \\
$4 \mathrm{R}$ & 68 & 1 & - \\
2 E & 24 & - & - \\
$4 \mathrm{E}$ & 12 & & \\
\hline
\end{tabular}

\section{Discussion}

Kerosene which is produced at the government-owned Ceylon Petroleum Corporation refinery near Colombo is distributed to depots throughout the country and from there it is supplied to co-operative stores and other retail outlets from where the households obtain their requirements. The co-operative stores supply the kerosene to the consumer either on payment of cash or in exchange for kerosene stamps, and the quantity obtained by the consumer on any visit to the store is very variable; depending on his economic circumstances, a householder may sometimes purchase as little as $100 \mathrm{ml}$ at a time. 
According to data published by the Ceylon Petroleum Corporation for the period 1970 to $1980,{ }^{1}$ there were fluctuations in the total quantity of kerosene sold each year; the highest was recorded in 1972 when 278157 tonnes were consumed and the lowest in 1980 (188 288 tonnes). More recent data available at the Corporation showed that in 1982 the quantity of kerosene sold was 174090 tonnes and in 1983 (up to October) it was 133380 tonnes. $^{2}$ On a proportionate basis the output for the whole of 1983 would work out to 160056 tonnes. The present study gives an estimated consumption for 1983 of $264 \times 10^{8}$ litres or 207400 tonnes* which, surprisingly, is higher than what is expected to be the output figure for 1983.

Fernando et al who have made a study of the kerosene consumption pattern in Sri Lanka based on sales data have worked out a series of values which are said to indicate the quantity of kerosene required to meet the essential household needs of the population for each year in the period $1970-1980 .{ }^{6}$ The quantity for 1980 is estimated at 206600 tonnes which is higher than the quantity sold in that year. Using the same index and the estimated 1983 population, the quantity of kerosene required to meet the basic needs in 1983 works out to 214900 tonnes. At present, with the high market price of kerosene, very few households use it for cooking, and the essential household needs may be considered as being almost totally represented by the quantity that is required for lighting.

In the present study half the number of sample households were found to be receiving kerosene stamps - a result which agrees with the national data available in the Department of the Food Commissioner which operates the kerosene stamp scheme? Although kerosene stamps are meant to provide kerosene up to a certain value per month free to a household, in reality there is an opportunity cost attached to the kerosene obtained on stamps as the householder could alternatively take certain types of foodstuffs free instead of the kerosene. ${ }^{\dagger}$ It is therefore possible that in times of financial stress, many households forego the kerosene in favour of foodstuifs and so cause a reduction in kerosene consumption. Such a trend would manifest itself if kerosene consumption in selected households is monitored over a prolonged period of several days or weeks. This may account, in some measure, for the estimate in this study being higher than what is expected to be the supply figure of the Ceylon Petroleum Corporation while yet falling a little short of the hypothetical estimate of the quantity required to supply the essential household needs of the population. It is also possible that the quantity of kerosene actually being marketed in the country exceeds the sales figures given by the Corporation, and if this is so, it would have contributed to the observed discrepancy. Whatever may be the reason for the difference, the magnitude of the estimate of consumption in this study shows that most of the kerosene supplied by the Corporation goes for direct use as household lighting fuel.

\footnotetext{
* Converted into tonnes using the Corporation's factors: 4.546 litres $=1$ gallon;
280 gallons $=1$ tonne.

$广$ At the time of writing, the value of a kerosene stamp was Rs. 21.73. Each month the household exchanges a stamp for either kerosene or foodstuffs at the local co-operative store; the store surrenders its collection of kerosene stamps to the Food Commissioner's Department and obtains cash reimbursement up to the amount covered by the stamps.
} 
A Quantitative Study of the Direct Use of Kerosene for Lighting in Sri Lanka Households

\section{Conclusions}

1. This study has shown that most of the kerosene consumed in the country is used for lighting in households and that kerosene consumption for lighting is heaviest $(84 \%$ of the estimate) in rural areas.

2. The bottle lamp (without chimney) is the most common type of lamp used.

3. In the rural sector more than half $(62 \%)$ of the households and in the urban sector a much smaller proportion $(19 \%)$ receive kerosene stamps.

\section{Acknowledgements}

The writer wishes to express his thanks to the Natural Resources, Energy and Science Authority of Sri Lanka for having provided the funds and other resources for carrying out this study, to J. A. Chandrasiri and M. A. N. Gunaratne, Staff Assistants, for having carried out the field work and helped in the analysis of the data, and to Valentine Abeywardena, former Biometrician of the Coconut Research Institute, for his help and guidance in the statistical work.

\section{References}

1. CEYLON PETROLEUM CORPORATION (1981) Petroleum Statistics of Sri Lanka 1970-1980, 31p. Planning \& Economics Section, Ceylon Petroleum Corporation, Colombo 3.

2. CEYLON PETROLEUM CORPORATION (1984) Unpublished data. Planning and Economics Section, Ceylon Petroleum Corporation, Colombo 3.

3. DIRECTOR OF CENSUS AND STATISTICS (1981). Census of population and housing, Sri Lanka, Preliminary release No. 1, 31p. Department of Census and Statistics, Colombo 7.

4. DIRECTOR OF CENSUS AND STATISTICS (1982) Housing tables, Preliminary release no. 3, 75p. Department of Census \& Statistics, Colombo 7.

5. DIRECTOR OF CENSUS AND STATISTICS (1983) Unpublished data. Department of Census \& Statistics, Colombo 7.

6. FERNANDO, G.B.A., CHANDRASEKERA D., JAYASEKERA, D.M. \& SEPALAGE B.P. (1981) Sri Lanka energy sector study - Asian Development Bank regional energy survey (mimeo), Ministry of Finance \& Planning, Colombo 1.

7. FOOD COMMISSIONER (1983) Unpublished data. Department of the Food Commissioner, Colombo 2.

8. SANKAR T. L. \& FERNANDO, G.B.A. (1978). Towards an energy policy in Sri Lanka (mimeo), 259 p. Ministry of Finance \& Planning, Colombo 1.

9. UNDP/WORLD BANK (1982). Sri Lanka Issues and Options in the Energy Sector, 102 p. UNDP/World Bank Energy Section Programme, Report no. 3794-CE.

10. WIJESINGHE, L.C.A. DE S. (1984). A Sample Study of Biomass Fuel Consumption in Sri Lanka Households. Biomass, 5, 259—280. 